\title{
$\mathrm{O}$ к ВИЧ-инфицированным: страх или помощь?
}

Хрянин А. А. ${ }^{1,2,}{ }^{*}$, Решетников О. В. ${ }^{3}$, Шпикс Т. А. ${ }^{1}$, Бочарова В. К. ${ }^{1}$, Русских М. В. ${ }^{1}$, Маринкин И. $0 .{ }^{1}$

${ }^{1}$ Новосибирский государственный медицинский университет Министерства здравоохранения Российской Федерации 630091, Российская Федерация, г. Новосибирск, Красный просп., д. 52

${ }^{2}$ Ассоциация акушеров-гинекологов и дерматовенерологов

630004, Российская Федерация, г. Новосибирск, ул. Ленина, д. 55

${ }^{3}$ Научно-исследовательский институт терапии и профилактической медицины — филииал Института цитологии и генетики Сибирского отделения Российской академии наук

630089, Российская Федерация, г. Новосибирск, ул. Бориса Богаткова, д. 175/1

Исследование было проведено в 2017-2018 годах путем анонимного анкетирования. В нем приняли участие 838 студентов 4-го курса лечебного, педиатрического, стоматологического и медико-профилактического факультетов. Для опроса были использованы две анкеты: адаптированная анкета, созданная на основе типового опросника ЮНЭЙДС, и анкета-опросник по методике диагностики коммуникативной толерантности В. В. Бойко. Обнаружено, что студенты-медики не осуждают ВИЧ-инфицированных людей, не считают, что люди с положительным ВИЧ-статусом обязательно ведут себя безнравственно и поэтому заслуживают это заболевание. Студенты-медики показали высокий уровень профрессиональной коммуникативной толерантности и готовность помогать этим пациентам, хотя сами при этом испытывают страх заражения во время лечебных манипуляций. Установлено незнание ряда правовых вопросов, касающихся ВИЧ-инфицированных пациентов.

Ключевые слова: ВиЧ-инфекция, студенты-медики, стигматизация, коммуникативная толерантность

Конфрликт интересов: авторы заявляют об отсутствии потенциального конфрликта интересов, требующего раскрытия в данной статье.

Для цитирования: Хрянин А. А., Решетников О. В., Шпикс Т. А., Бочарова В. К., Русских М. В., Маринкин И. О. Отношение студентов-медиков к ВИЧ-инфицированным: страх или помощь? Вестник дерматологии и венерологии. 2019;95(4):40-47. https://doi.org/10.25208/0042-4609-2019-95-4-40-47 


\section{The attitude of medical students towards HIV-infected people: fear or help?}

Alexey A. Khryanin $n^{1,2,}$, Oleg V. Reshetnikov ${ }^{3}$, Tatiana A. Shpiks ${ }^{1}$, Valentina K. Bocharova', Maria V. Russkikh', Igor 0. Marinkin ${ }^{1}$

${ }^{1}$ Novosibirsk State Medical University, Ministry of Health of the Russian Federation Krasnyy prospect, 52, Novosibirsk, 630091, Russian Federation

${ }^{2}$ Association of Obstetricians-Gynecologists and Dermatovenerologists

Lenina str., 55, Novosibirsk, 630004, Russian Federation

${ }^{3}$ Research Institute for Treatment and Preventive Medicine - a branch of the Institute of Cytology and Genetics, Siberian Branch of Russian Academy of Sciences

Borisa Bogatkova str., 175/1, Novosibirsk, 630089, Russian Federation

The study was conducted during the 2017-2018 period using the method of anonymous questionnaire. In total, 838 4-year-students from medical, pediatric, dental and medical-prophylactic departments participated in the study. Two questionnaires were used for the survey: an adapted version of the standard UNAIDS questionnaire and that based on V. V. Boyko's methodology of diagnosing communicative tolerance. It is found that medical students do not condemn HIV-infected people, nor believe that people with a positive HIV status necessarily behave immorally, thus deserving this disease. Medical students show a high level of professional communicative tolerance and readiness to help these patients, although being afraid of getting the infection during medical manipulations. At the same time, a low level of awareness concerning a number of legal issues regarding HIV-infected patients has been established.

Keywords: HIV infection, medical students, stigmatization, communicative tolerance

Conflict of interest: the authors state that there is no potential conflict of interest requiring disclosure in this article.

For citation: Khryanin A. A., Reshetnikov O. V., Shpiks T. A., Bocharova V. K., Russkikh M. V., Marinkin I. O. The attitude of medical students towards HIV-infected people: fear or help? Vestnik Dermatologii i Venerologii. 2019;95(4):40-47. https://doi.org/10.25208/0042-4609-2019-95-4-40-47 


\section{Введение}

С 1987 года идет неуклонный, быстро прогрессирующий рост числа людей, зараженных ВИЧ в России. В. В. Покровский и соавт. (2008) рассматривали эпидемическую ситуацию по ВИЧ-инфекции как стабильно ухудшающуюся [1]. Этот прогноз, к несчастью, сбылся для большинства регионов и РФ в целом - к 2010 году на территории Российской Федерации было зарегистрировано 600 тысяч человек, живущих с ВИЧ-инфекцией, а к концу 2019 года - в два раза больше [2]. Основными лидирующими путями передачи ВИЧ в России являются парентеральный контакт при употреблении наркотиков и гетеросексуальный контакт. Снижения распространения вируса можно было достигнуть путем значительного расширения целенаправленных программ профилактики и терапии [3]. При этом основной проблемой такого подхода, к примеру, среди потребителей инъекционных наркотиков является то, что ВИЧ-инфицированные наркоманы предпочитают не раскрывать свой статус из-за выраженной стигматизации в обществе [4, 5]. Проблема стигматизации, дискриминации ВИЧ-больных в обществе крайне актуальна. В некоторых странах уже задокументирован отказ в медицинской помощи ВИЧ-больным [6].

Западная Сибирь - один из основных регионов с большим количеством ВИЧ-инфицированных лиц. Участковые врачи являются основным звеном, которое осуществляет первый контакт с ВИЧ-инфиццированными. Однако пока неясно, насколько врачи общей практики подготовлены к общению с ВИЧ-инфицированными лицами. В свою очередь, эффрективное общение врача с пациентом может оказаться решающим в фрормировании позитивного отношения пациента к лечению и в значительной степени повлиять на эффективность будущих лечебных мероприятий.

Со слов опрашиваемых, в исследовании индекса стигмы из Новосибирска ВИЧ-положительным людям также приходилось сталкиваться с различными вариантами дискриминации, в том числе и с отказом в медицинской помощи по причине их ВИЧ-статуса [7].

Негативное отношение к ВИЧ-инорицированным со стороны медицинских работников проявляется в изоляции этих пациентов, нарушении конфиденциальности, отказе в медицинской помощи, тестировании на ВИЧ без позволения самого пациента. Такое поведение объясняется наличием множества заблуждений и ошибочных стереотипов относительно ВИЧ-инфекции, нехваткой знаний и обычным страхом [8]. Существует ряд исследований, показывающих, что качественные знания о ВИЧ, путях его передачи, полученные в университете, приводят к снижению стигматизированного отношения к ВИЧ-инфицированным $[9,10]$.

Поэтому целью нашего исследования являлись оценка знаний и отношения студентов медицинского вуза к ВИЧ-инфицированным.

\section{Материалы и методы}

Исследование было проведено в 2017-2018 годах путем анонимного анкетирования. В исследовании приняли участие 838 студентов 4 курса лечебного, педиатрического, стоматологического и медико-профилактического фракультетов НГМУ. Лечебный фракультет (всего 441 студент, среди них 221 юноша, 220 девушек), педиатрический фракультет (всего 281 студент, среди них юношей 76, девушек 205), стоматологический фракультет (всего 102 студента, среди них юношей 40, девушек 62), медико-профилактический фракультет (всего 14 студентов, среди них юношей 11, девушек 3).

Для опроса была использована адаптированная анкета, созданная на основе типового опросника ЮНЭЙДС [11]. Анкета содержала 2 части. Первая часть состояла из вопросов, касающихся социальных данных и основных источников получения знаний на тему ВИч/ СПИД. Вторая часть состояла из двух подгрупп вопросов. Первой группой вопросов оценивались убеждения респондента относительно тестирования, конфиденциальности, раскрытия информации и условиях оказания помощи пациентам с ВИЧ/СПИД, а второй группой - отношение к оказанию помощи пациенту с ВИЧ/ СПИД. Также оценивалось отношение студентов к самим ВИЧ-положительным людям и информированность студентов в отношении ВИЧ-инфекции и путей ее распространения. Анализ данных, полученных в процессе анкетирования, проводился с помощью программы статистического анализа. Оценивались критерий хи-квадрат и независимый т-критерий Стьюдента. Статистическая значимость была установлена как $p<0,05$.

\section{Результаты и обсуждение}

Опрос показал, что основным источником информации для студентов является интернет. Данный вид получения информации выбрало большинство студентов (73,8 \%), что неудивительно, учитывая скорость появления новой информации в интернете и приверженность современной молодежи к поиску необходимых сведений в электронных источниках. Вторым по популярности способом получения знаний для студентов обоих фракультетов явилось знакомство с результатами научных исследований, посвященных ВИЧ/СПИД (44,8 \%). Следующим по популярности методом получения инорормации о ВИЧ/СПИД оказалось участие в мероприятиях, посвященных данной тематике (37 \%). Чтение журналов, книг не пользовалось особой популярностью среди учащихся. Что касается практического опыта общения с ВИЧ-инфрццированными, то 32 \% опрошенных студентов оказывали помощь человеку с ВИЧ/СПИД, при этом только $21 \%$ студентов проходил курсы по оказанию помощи лицу с ВИЧ/СПИД. Аналогичная ситуация наблюдается не только в нашей стране. Имеются данные, что, например, в Малайзии студенты также испытывают недостаток практического опыта, однако, в отличие от российских студентов, у них наблюдается довольно хорошая мотивированность к изучению данной темы [8].

Студенты практически единодушно считают, что тестирование на ВИЧ должно регулярно проводиться для всех пациентов как часть процесса приема (табл. 1). При этом бо́льшая часть обучающихся согласилась с тем, что можно тестировать пациента на ВИЧ без его ведома при определенных обстоятельствах. Также студенты уверены, что все медицинские работники должны проходить регулярное обследование на ВИЧ.

Студенты согласились с тем, что медицинских работников необходимо уведомлять о ВИЧ-статусе пациента, чтобы они могли обезопасить себя. Большинство студентов (76,6 \%) выразили свое несогласие (табл. 2) с возможностью допуска ВИЧ-инфицированного медицинского работника к работе в любой сфере здравоохранения, подразумевающей прямой контакт с пациентом, 
Таблица 1. Этические убеждения учащихся в области здравоохранения о тестировании, конфиденциальности и раскрытии информации, а также условиях оказания помощи пациентам с ВИЧ/СПИД

Table 1. Medical students' ethical beliefs with regard to testing, confidentiality and disclosure, as well as about caring for HIV/AIDS patients

\begin{tabular}{|c|c|c|c|}
\hline & Согласен & Равнодушен & Не согласен \\
\hline $\begin{array}{c}\text { Существуют обстоятельства, при которых целесообразно тестировать пациента } \\
\text { на ВИЧ/СПЙДез его ведома или разрешения }\end{array}$ & $724(86 \%)$ & $44(5 \%)$ & $70(9 \%)$ \\
\hline Все медицинские работники должны регулярно проходить обследование на ВИЧ/СпИД & $825(98,6 \%)$ & $5(0,5 \%)$ & $8(0,9 \%)$ \\
\hline $\begin{array}{c}\text { Тестирование на ВИЧ/СПИД должно регулярно проводиться как часть процесса приема } \\
\text { для всех пациентов }\end{array}$ & $771(92 \%)$ & $30(3,5 \%)$ & $37(4,5 \%)$ \\
\hline $\begin{array}{c}\text { Родственники пациента должны быть уведомлены о ВиЧ-статусе пациента, } \\
\text { даже без разрешения пациента на это }\end{array}$ & $475(56 \%)$ & $70(9 \%)$ & $293(35 \%)$ \\
\hline $\begin{array}{c}\text { Сексуальные партнеры пациентов с вич/СПИД должны быть уведомлены о статусе } \\
\text { пациента, даже без разрешения пациента на это }\end{array}$ & $727(86,6 \%)$ & $30(3,6 \%)$ & $81(9,6 \%)$ \\
\hline $\begin{array}{c}\text { Медицинский персонал несет ответственность за информирование супруга/партнера } \\
\text { или друга/подругу о ВИЧ-статусе пациента }\end{array}$ & $524(62,5 \%)$ & $103(12,3 \%)$ & $211(25,2 \%)$ \\
\hline $\begin{array}{c}\text { Палаты/кровати пациентов с ВИч/СПИД должны быть четко обозначены, } \\
\text { чтобы сотрудники больницы знали о статусе пациента }\end{array}$ & $429(51,2 \%)$ & $71(8,5 \%)$ & $338(40,3 \%)$ \\
\hline $\begin{array}{c}\text { Медицинские карты пациентов с ВИЧ/СПИД должны быть четко обозначены, } \\
\text { чтобы сотрудники больницы знали о статусе пациента }\end{array}$ & $747(89,1 \%)$ & $31(3,7 \%)$ & $60(7,2 \%)$ \\
\hline
\end{tabular}

Таблица 2. Убеждения студентов относительно политики в области здравоохранения для медицинских работников

Table 2. Medical students' beliefs with regard to healthcare policy for medical staff

\begin{tabular}{|c|c|c|c|}
\hline & Согласен & Равнодушен & Не согласен \\
\hline $\begin{array}{c}\text { Медицинских работников следует уведомлять о ВИЧ-статусе пациента, чтобы они могли } \\
\text { обезопасить себя }\end{array}$ & $803(95,8 \%)$ & $15(1,8 \%)$ & $20(2,4 \%)$ \\
\hline $\begin{array}{l}\text { Медицинских работников с ВИЧ/СПИД следует допускать к работе в любой сфере } \\
\text { здравоохранения, которая подразумевает прямой контакт с пациентом }\end{array}$ & $205(24,4 \%)$ & $112(13,4 \%)$ & $521(62,2 \%)$ \\
\hline $\begin{array}{c}\text { Медицинским работникам, инфицированным ВиЧ, должно быть разрешено выполнять } \\
\text { инвазивные процедуры, такие как забор крови или иньекции }\end{array}$ & $128(15,3 \%)$ & $68(8,1 \%)$ & $642(76,6 \%)$ \\
\hline
\end{tabular}

Таблица 3. Отношение студентов медицинских вузов к оказанию помощи больным с ВИЧ-инфекцией

Table 3. Medical students' attitudes towards assistance of HIV patients

\begin{tabular}{|c|c|c|c|}
\hline & Согласен & Равнодушен & Не согласен \\
\hline $\begin{array}{c}\text { Я обеспокоен тем, что я недостаточно обучен надлежащим навыкам консультирования } \\
\text { пациентов с ВИЧ-инфекцией }\end{array}$ & $504(60,1 \%)$ & $166(19,8 \%)$ & $168(20,1 \%)$ \\
\hline $\begin{array}{c}\text { Я обеспокоен тем, что подвергаюсь порицанию моей семьей, потому что должен } \\
\text { оказывать помощь пациентам с ВИЧ-инфекцией }\end{array}$ & $129(15,3 \%)$ & $217(26 \%)$ & $492(58,7 \%)$ \\
\hline $\begin{array}{c}\text { Я обеспокоен тем, что подвергаюсь порицанию моими друзьями, потому что должен } \\
\text { оказывать помощь пациентам с ВИЧ-инфрекцией }\end{array}$ & $115(13,7 \%)$ & $226(27 \%)$ & $497(59,4 \%)$ \\
\hline $\begin{array}{l}\text { Мне было бы более комфортно оказывать помощь пациентам без ВИЧ-инфекции, } \\
\text { чем пациентам с ВИЧ-инфекцией }\end{array}$ & $545(65 \%)$ & $165(19,6 \%)$ & $173(20,4 \%)$ \\
\hline Я откажусь от лечения пациента с ВИЧ-инфекцией в целях защиты себя и своей семьи & $186(22,1 \%)$ & $160(19 \%)$ & $492(58,9 \%)$ \\
\hline Я могу попытаться избежать ухода за больными ВИЧ/СПИД & $297(35,4 \%)$ & $178(21,2 \%)$ & $363(43,3 \%)$ \\
\hline Я чувствую себя некомфортно в окружении людей, больных ВИЧ/СПИД & $271(36 \%)$ & $226(30 \%)$ & $251(34 \%)$ \\
\hline Мне было бы некомфоортно оказывать помощь члену семьи с ВИЧ-инфекцией & $195(23,2 \%)$ & $188(22,4 \%)$ & $455(54,3 \%)$ \\
\hline $\begin{array}{l}\text { Я боюсь заразиться ВИЧ, если мне приходится оказывать помощь больным } \\
\text { С ВИЧ-инфекцией }\end{array}$ & $553(66 \%)$ & $88(10,5 \%)$ & $197(23 \%)$ \\
\hline
\end{tabular}

и разрешения им выполнения инвазивных процедур. Бо́льшая часть студентов обеспокоена недостаточным обучением в вузе навыкам консультирования ВИЧ-инфрицированных (табл. 3). Выявлены тенденции к избеганию любого профессионального контакта с больными ВИЧ-инфекцией. Учащиеся (65 \%) признались, что им было бы более комфрортно оказывать помощь человеку без ВИЧ-инфекции, при этом 1/3 студентов (35 \%) будут пытаться избегать ухода за ВИЧ-инфицированными, а $1 / 4$ студентов $(22,1 \%)$ откажутся от лечения больного при наличии у него ВИЧ-инфекции. Также был выявлен фракт того, что страх заразиться ВИЧ при оказании помощи ВИЧ-положительному пациенту присутствует у большинства студентов (66 \%). 
С утверждением о некомфрортном ощущении себя в окружении ВИЧ-инфицированных согласилась примерно 1/3 всех студентов, 1/3 ответила равнодушием и еще $1 / 3$ несогласием. Хотя при оказании помощи члену семьи с ВИЧ-инфекцией большинство студентов не испытывало бы дискомфорта.

Мнение студентов о лицах с ВИЧ-положительным статусом представлено в таблице 4. Заслуживает внимания установленное в целом позитивное отношение студентов к ВИЧ-инфицированным пациентам. Студенты не согласились с утверждениями о том, что люди с ВИЧ/СПИД ведут себя безнравственно и заслуживают это заболевание; что можно определить положительный ВИЧ-статус по внешности человека; что лечение пациентов с ВИЧ - это бессмысленные затраты ресурсов; что ближайшее окружение студентов порицает ВИЧ-положительных людей; что пациенты с ВИЧ в целом получают менее качественную медицинскую помощь. Опрашиваемые согласились с мнением о том, что человек, который выглядит здоровым, может быть инфицирован ВИЧ, что большинство людей воспринимают ВИЧ-инфицированных как изгоев, что консультирование может улучшить качество жизни пациентов с ВИЧ/СПИД, а лечение оппортунистических инфекций может продлить их жизнь.

Данная работа явилась первым многоплановым исследованием отношения студентов-медиков к проблеме ВИЧ-инфицированных лиц в Российской Федерации. Исследование позволило выявить приоритеты студентов в отношении различных медицинских, этических и правовых аспектов стигматизации ВИЧ-инфицированных.

Полученные результаты оказались далеко не однозначными. В целом студенты-медики проявляют положительное отношение к ВИЧ-инфицированным пациентам. Они не осуждают этих людей, не считают, что люди с положительным ВИЧ-статусом обязательно ведут себя безнравственно и поэтому заслуживают это заболевание. Это говорит о моральной зрелости студентов, их понимании проблемы и отсутствии предвзятого и стереотипного мышления. И еще один немаловажный фракт, что ближайшее окружение студентов не порицает людей с ВИЧ, а это значит, что, скорее всего, именно влияние самих учащихся на своих друзей и близких, донесение пра- вильной информации позволило сформировать верные убеждения среди их окружения. Тот фракт, что студенты указывали на то, что бо́льшая часть людей воспринимает ВИЧ-инфицированных как изгоев, подтверждает необходимость донесения до широких масс правильной информации о ВИЧ. Радует тот факт, что студенты поддерживают лечение ВИЧ-больных, не считая это бессмысленной тратой ресурсов. Однако студенты обнаружили незнание правовых аспектов проблемы. Например, большинство студентов согласились с высказыванием о том, что все медицинские работники должны регулярно сдавать тест на ВИЧ. Также студенты подтвердили то, что считают приемлемым рутинное проведение анализа на ВИЧ при приеме всех пациентов. При этом в рекомендациях центра по контролю и предупреждению заболеваний прямо указано, что тестирование должно проводиться только с согласия пациентов после обширной консультации до и после тестирования [12].

Также большинство студентов согласились с тем, что родственники ВИЧ-положительного пациента должны быть уведомлены о его статусе, даже без разрешения пациента. Это не соответствует законодательству РФ, так как статус пациента может быть оглашен другим гражданам, в том числе его родственникам, только с явного согласия пациента [13].

Обнаружена готовность наших студентов сообщать о ВИЧ-статусе сексуальным партнерам пациента без разрешения последнего. Это еще одно нарушение сложившихся правил в России, по которым супруг/супруга пациента может быть проинформирована о статусе последнего, только если он сам не хочет говорить об этом и при условии получения согласия от пациента. Аналогично большинство студентов согласилось с маркировкой палат/коек и медицинских карт ВИЧ-инфиццированных.

Ответы на вопросы анкеты указывают на то, что бо́льшая часть студентов испытывает страх заразиться при оказании помощи ВИЧ-инфицированным. Этим страхом объясняется готовность уклониться от помощи ВИЧ-положительным пациентам.

С целью уточнения возможных причин дистанцирования студентов от ВИЧ-инфицированных пациентов мы исследовали уровень профессиональной коммуникативной толерантности будущих врачей.

Таблица 4. Мнение студентов медицинских вузов о людях с ВИЧ-положительным статусом

Table 4. Medical students' opinions about HIV-positive people

\begin{tabular}{|c|c|c|c|}
\hline & Согласен & Равнодушен & Не согласен \\
\hline Многие люди с ВИЧ/СПИДом ведут себя безнравственно и заслуживают это заболевание & $99(11,8 \%)$ & $131(15,6 \%)$ & $608(72,5 \%)$ \\
\hline $\begin{array}{l}\text { Людям, инфицированным ВИЧ/СПИДом, стоит находиться в отдельных палатах } \\
\text { госпиталя/клиники }\end{array}$ & $373(44,5 \%)$ & $150(17,9 \%)$ & $315(37,6 \%)$ \\
\hline Положительный ВИЧ/СПИД статус человека можно определить по его/ее внешности & $102(12,1 \%)$ & $75(8,9 \%)$ & $661(78,9 \%)$ \\
\hline Человек, который выглядит здоровым, может быть инфицирован ВИЧ/СПИД & $789(94,2 \%)$ & $21(2,5 \%)$ & $28(3,3 \%)$ \\
\hline Лечение пациентов с ВИЧ/СПИД - это бессмысленные затраты ресурсов & $44(5,2 \%)$ & $76(9 \%)$ & $718(85,8 \%)$ \\
\hline Большинство людей воспринимают ВИЧ/СПИД-инфицированных пациентов как изгоев & $606(72,3 \%)$ & $126(15 \%)$ & $106(12,7 \%)$ \\
\hline Мое окружение порицает людей с положительным ВИЧ/СпИД-статусом & $160(19 \%)$ & $273(32,5 \%)$ & $405(48,5 \%)$ \\
\hline В целом пациенты с ВИЧ/СПИДом получают менее качественную медицинскую помощь & $146(17,4 \%)$ & $161(19,2 \%)$ & $531(63,3 \%)$ \\
\hline Консультирование может улучшить качество жизни пациентов с ВИЧ/СПИДом & $738(88 \%)$ & $67(7,9 \%)$ & $33(3,9 \%)$ \\
\hline Лечение оппортунистических инфекций может продлить жизнь пациента с ВИч/СпИДом & $739(88,1 \%)$ & $72(8,5 \%)$ & $27(3,4 \%)$ \\
\hline
\end{tabular}


Коммуникативная толерантность является элементом профессиональной коммуникативной компетентности специалиста. Коммуникативная компетентность врача - умение эфрфективно общаться с пациентом оказывается одним из важнейших профессионально важных качеств личности современного врача, фрактором успешности врачебной деятельности и нередко оценивается пациентами даже выше, чем его профрессиональные знания [14].

Было проведено анонимное анкетирование 472 студентов НГМУ, среди них - 155 студентов педиатрического факультета, 232 студента лечебного факультета и 85 студентов стоматологического фракультета. Для оценки уровня коммуникативной толерантности была использована методика В. В. Бойко. Опросник Бойко состоит из 45 вопросов-утверждений, сгруппированных в 9 шкал. Респонденты должны были оценить, насколько данные утверждения верны по отношению к ним, используя баллы от 0 до 3. Чем больше набрано баллов, тем ниже степень толерантности. Максимальное количество баллов, которое можно набрать, ответив на все вопросы анкеты, 135; максимальное количество баллов за каждую из шкал - 15.

Шкала 1. Неприятие или непонимание индивидуальности человека.

Шкала 2. Использование себя в качестве эталона при оценках других.

Шкала 3. Категоричность или консерватизм в оценках людей.

Шкала 4. Неумение скрывать или сглаживать неприятные чувства.

Таблица 5. Степень коммуникативной толерантности по В. В. Бойко Table 5. Degree of communicative tolerance according to Boyko's methodology of diagnosing

\begin{tabular}{cccc}
\hline $1-45$ баллов & $45-85$ баллов & $85-125$ баллов & $\begin{array}{c}125-135 \\
\text { баллов }\end{array}$ \\
\hline $\begin{array}{c}\text { Высокая } \\
\text { степень } \\
\text { толерантности }\end{array}$ & $\begin{array}{c}\text { Средняя } \\
\text { степень }\end{array}$ & $\begin{array}{c}\text { Низкая } \\
\text { степень }\end{array}$ & $\begin{array}{c}\text { Полное } \\
\text { неприятие }\end{array}$ \\
\hline
\end{tabular}

Шкала 5. Стремление переделать, перевоспитать партнера по общению.

Шкала 6. Стремление подогнать других под себя.

Шкала 7. Неумение прощать другому ошибки.

Шкала 8. Нетерпимость к дискомфортным (болезнь, усталость, отсутствие настроения) состояниям партнера по общению.

Шкала 9. Неумение приспосабливаться к другим участникам общения.

Полученные результаты по всему опроснику и по отдельным шкалам представлены в таблице 6.

Обращает на себя внимание тот факт, что студенты продемонстрировали достаточно выраженную коммуникативную толерантность: студенты педиатрического и стоматологического фракультетов оказались в границах высокой толерантности, студенты лечебного факультета, набрав немного больше баллов, оказались в границах средней степени толерантности. Недостаточно высокая степень толерантности у студентов лечебного фракультета проявилась в шкалах, касающихся непринятия индивидуальности другого человека, категоричности в оценках других людей, стремления подогнать партнера под себя, неумения прощать другому ошибки. При этом в шкале, посвященной отношению к дискомфортным состояниям пациента, была выявлена самая высокая степень толерантности среди других шкал у студентов всех трех фракультетов.

Средняя степень профессиональной коммуникативной толерантности и высокие баллы в некоторых шкалах, обнаруженные у студентов лечебного факультета, могут оказаться причиной формирования некоторых предубеждений относительно больных, основанных на категоричности мышления, непонимании и неготовности принять человека со всеми его особенностями. Это свидетельствует о необходимости ведения занятий по психологии общения для студентов старших курсов.

Установленная в ходе исследования высокая толерантность студентов к дискомфортным состояниям пациентов указывает на развитое чувство эмпатии и выраженную способность сопереживать, что является важной чертой личности будущего врача

Таблица 6. Средний балл по анкете В. В. Бойко

Table 6. Average score according to Boyko's questionnaire

\begin{tabular}{ccccc}
\hline & $\begin{array}{c}\text { Педиатрический } \\
\text { факультет }\end{array}$ & $\begin{array}{c}\text { Лечебный } \\
\text { факультет }\end{array}$ & $\begin{array}{c}\text { Стоматологический } \\
\text { факультет }\end{array}$ & $\begin{array}{c}\text { В среднем по } \\
\text { каждой шкале }\end{array}$ \\
\hline Шкала 1. Неприятие или непонимание индивидуальности человека & 5,25 & 5,81 & 4,78 & $5(5,28)$ \\
\hline Шкала 2. Использование себя в качестве эталона при оценках других & 4,56 & 4,95 & 4,54 & $5(4,68)$ \\
\hline Шкала 3. Категоричность или консерватизм в оценках людей & 5,48 & 5,80 & 4,72 & $5(5,33)$ \\
\hline Шкала 4. Неумение скрывать или сглаживать неприятные чувства & 5,12 & 5,35 & 4,74 & $5(5,07)$ \\
\hline Шкала 5. Стремление переделать, перевоспитать партнера по общению & 4,73 & 4,93 & 3,88 & $4,5(4,51)$ \\
\hline Шкала 6. Стремление подогнать других под себя & 5,37 & 5,78 & 3,97 & $5(5,0,4)$ \\
\hline Шкала 7. Неумение прощать другому ошибки & 5,03 & 5,86 & 4,44 & $5(5,11)$ \\
\hline Шкала 8. Нетерпимость к дискомфрортным (болезнь, усталость, & 3,27 & 3,68 & 3,10 & $3(3,35)$ \\
\hline отсутствие настроения) состояниям партнера по общению & 4,33 & 4,87 & 4,58 & $5(5,00)$ \\
\hline Шкала 9. Неумение приспосабливаться к другим участникам общения & 43 & 47 & 39 & 43 \\
\hline В среднем по всей анкете & & &
\end{tabular}

Примечание: средний бал по всем факультетам - $43+47+49 / 3=43$ (высокая степень толерантности).

Note: The average score for all the departments equals $43+47+49 / 3=43$ (a high degree of tolerance). 


\section{Заключение}

Исследованием установлено, что студенты-медики не осуждают ВИЧ-инфицированных людей, однако они испытывают страх заражения, что приводит к отказу от помощи ВИЧ-позитивным пациентам. При этом студенты обладают развитым чувством эмпатии и достаточно высоким уровнем профессиональной коммуникативной толерантности, что является важным фрактором успешности в их будущей профрессиональной деятельности. Склонность к стигматизации связана не с неправильными моральными установками, а со страхом заражения и незнанием некоторых правовых аспектов проблемы. Обнаружено, что студенты имеют в основном неверные установки в отношении тестирования, конфриденциальности, раскрытия информации и условий оказания помощи людям с ВИЧ-инфекцией, которые не соответствуют нормативным законодательным актам. Отношение к оказанию медицинской помощи ВИЧ-больным также довольно неблагоприятное. Полученные результаты доказывают необходимость расширения и дополнения данной темы в обучающих программах студентов медицинских вузов.

\section{Литература/References}

1. Покровский В. В. ВИЧ/СПИД в России: ситуация и прогноз. Эпидемиология и инфекционные болезни. 2008;3:4-12. [Pokrovskiy V. V. HIV/AIDS in Russia: situation and prognosis. Epidemiology and infectious diseases. 2008;3:4-12. (In Russ.)]

2. Беляков Н. А., Рассохин В. В., Розенталь В. В., Огурцова С. В., Степанова Е. В., Мельникова Т. Н. и др. Эпидемиология ВИЧ-инфекции. Место мониторинга, научных и дозорных наблюдений, моделирования и прогнозирования обстановки. ВИЧ-инфекция и иммуносупрессии. 2019;11(2):7-26. [Belyakov N. A., Rassokhin V. V., Rosenthal, V. V., Ogurtsov S. V., Stepanova E. V., Melnikova T. N. et al. The Epidemiology of HIV infection. Place of monitoring, scientific and sentinel observations, modeling and forecasting of the situation. HIV infection and immunosuppression. 2019;11(2):7-26. (In Russ.)]. DOI: 10.22328/2077-9828-2019-11-2-7-26

3. Хеймер Р., Миллс Х. Л., Уайт Э., Викерман П., Колийн К. Моделирование эпидемии вируса иммунодесицита человека в Санкт-Петербурге. ВИЧ-инсеекция и иммуносупрессии. 2014;6(1):59-65. [Hamer R., Mills H. L., White E., Bikerman P., Colin K. Modeling of the human immunodeficiency virus epidemic in St. Petersburg. HIV infection and immunosuppression. 2014;6(1):59-65. (In Russ.)]

4. Багненко С. Ф., Дубикайтис П. А., Минаева Н. В., Рассохин В. В., Беляков Н. А. Структура обращений ВИЧ-инфицированных больных в стационар скорой помощи. ВИЧ-инфекция и иммуносупрессии. 2011;3(3):81-87. [Bagnenko S. F., Dubikaitis P. A., Minayeva N. V., Rassokhin V. V., Belyakov N. A. Structure of appeals of HIV-infected patients to the emergency hospital. HIV infection and immunosuppression. 2011;3(3):81-87. (In Russ.)]

5. Беляков Н. А., Багненко С. Ф., Дубикайтис П. А., Алимов Р. Р., Виноградова Т. Н. Результаты десятилетнего выявления ВИЧ-инфекции в стационаре скорой медицинской помощи. Медицинский академический журнал. 2014;14(2):48-54. [Belyakov N. A., Bagnenko S. F., Dubikaitis P. A., Alimov R. R., Vinogradova T. N. Results of ten-year detection of HIV infection in the emergency hospital. Medical academic journal. 2014;14(2):48-54. (In Russ.)]

6. UNAIDS Global report 2010. UNAIDS Report on the global AIDS epidemic 2010. http://www.unaids.org/globalreport/ global report.htm

7. Камалдинов Д. О., Касик Е. П., Уфимцев Д. Г. и др. Индекс стигмы людей, живущих с ВИЧ. Отчет по результатам социологического исследования. Новосибирск, 2014. [Kamaldinov D. O., Kasik E. P., Ufimtsev D. G. et al. Stigma Index of people living with HIV. Report on the results of sociological research. Novosibirsk, 2014. (In Russ.)]

8. Parker R., Aggleton P., Horizons F. HIV/AIDS-related stigma and discrimination: A conceptual framework and an agenda for action. Population Council, Washington, DC, USA, 2002.

9. Chan K. Y., Yang Y., Li Z. R., Stoove M. A., Reidpath D. D. Interrelationships between HIV/AIDS and risk behavior prejudice among medical students in Southern China. Current HIV Research. 2009;7(6):606-611.

10. Tan X., Pan J., Zhou D., Wang C., Xie C. HIV/AIDS knowledge, attitudes and behaviors assessmen to Chinese students: a questionnaire study. International Journal of Environmental Research and Public Health. 2007;4(3):248-253.

11. Choy K. K., Rene T. J., Khan S. A. Beliefs and attitudes of medical students from public and private universities in Malaysia towards individuals with HIV/AIDS. Scientific World Journal. 2013 Oct 29;2013:462826. DOI: 10.1155/2013/462826

12. Branson B. M., Handsfield H. H., Lampe M. A. Revised recommendations for HIV testing of adults, adolescents, and pregnant women in healthcare settings. Morbidity and Mortality Weekly Report. 2006:55(14):1-17.

13. Основы законодательства Российской Федерации об охране здоровья граждан от 22 июля 1993 г. № 5487-1, ст. 61. [Bases of the legislation of the Russian Federation on protection of health of citizens of July 22, 1993 № 5487-1, Art. 61. (In Russ.)]

14. Решетников А.В. Медико-социологический мониторинг: Руководство. М., 2003. [Reshetnikov A. V. Medical and sociological monitoring: Guidelines. Moscow, 2003. (In Russ.)] 


\section{Информация об авторах}

Алексей Алексеевич Хрянин* - д.м.н., профрессор кафедры дерматовенерологии и косметологии Новосибирского государственного медицинского университета Министерства здравоохранения Российской Федерации; вице-президент региональной общественной организации «Ассоциация акушеров-гинекологов и дерматовенерологов»; тел.: +7 (383) 222-32-04; e-mail: khryanin@mail.ru

Олег Вадимович Решетников - д.м.Н., В.Н.С. Научно-исследовательского института терапии и просиилактической медицины - филиала Института цитологии и генетики Сибирского отделения Российской академии наук; тел.: +7 (383) 201-24-93; e-mail: reshetnikov_ov@mail.ru

Татьяна Александровна Шпикс - к.м.н., доцент кафедры психологии и педагогики Новосибирского государственного медицинского университета Министерства здравоохранения Российской Федерации; тел.: +7 (383) 222-32-04

Валентина Константиновна Бочарова - студентка 6 курса педиатрического факультета Новосибирского государственного медицинского университета Министерства здравоохранения Российской Федерации; тел.: +7 (383) 222-32-04

Мария Викторовна Русских - аспирант Новосибирского государственного медицинского университета Министерства здравоохранения Российской Федерации; тел.: +7 (383) 222-32-04; e-mail: marie_le_mieux@mail.ru

Игорь Олегович Маринкин - д.м.н., профессор, ректор Новосибирского государственного медицинского университета Министерства здравоохранения Российской Федерации; тел.: +7 (383) 222-32-04; e-mail: rectorngmu@yandex.ru

\section{Information about the authors}

Alexey A. Khryanin* - Dr. Sci. (Med.), Prof., Department of Dermatovenerology and Cosmetology, Novosibirsk State Medical University, Ministry of Health of the Russian Federation; Vice-President, Regional Public Organization "Association of Obstetricians-Gynecologists and Dermatovenerologists"; tel.: +7 (383) 222-32-04; e-mail: khryanin@mail.ru

Oleg V. Reshetnikov - Dr. Sci. (Med.), Leading Researcher, Research Institute for Treatment and Preventive Medicine - a branch of the Institute of Cytology and Genetics, Siberian Branch of Russian Academy of Sciences; tel.: +7 (383) 201-24-93; e-mail: reshetnikov_ov@mail.ru

Tatiana A. Shpiks - Cand. Sci. (Med.), Assoc. Prof., Department of Psychology and Pedagogy, Novosibirsk State Medical University, Ministry of Health of the Russian Federation; tel.: +7 (383) 222-32-04

Valentina K. Bocharova - 6-year Medical Student, Pediatric Department, Novosibirsk State Medical University, Ministry of Health of the Russian Federation; tel.: +7 (383) 222-32-04

Maria V. Russkikh - Graduate Student, Novosibirsk State Medical University, Ministry of Health of the Russian Federation; tel.: +7 (383) 22232-04; e-mail: marie_le_mieux@mail.ru

Igor O. Marinkin - Dr. Sci. (Med.), Prof., Rector, Novosibirsk State Medical University, Ministry of Health of the Russian Federation; tel.: +7 (383) 222-32-04; e-mail: rectorngmu@yandex.ru 